\title{
Cardiovascular disease risk factors among undergraduate medical students in a tertiary care centre of eastern India: a pilot study
}

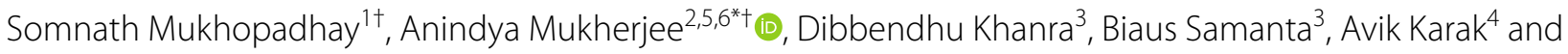
Santanu Guha ${ }^{4}$

\begin{abstract}
Background: Handful studies report the prevalence of cardiovascular disease (CVD) risk factors among medical students from India and none from the eastern part of the country.

Aim: To estimate the prevalence of risk factors of CVD and their correlation with CVD risk ratio among the MBBS students from eastern India.

Methods: 433 students were studied. International Physical Activity Questionnaire-long form was used for assessment of physical activity and Perceived Stress Scale (PSS) to elicit psychological stress levels. Waist-to-height ratio (WHtR) was calculated. Total cholesterol to high-density lipoprotein ratio was calculated as the CVD risk ratio.
\end{abstract}

Results: $39.3 \%$ were women and $68.6 \%$ of the subjects were in junior classes. $22.4 \%$ subjects had high PSS while $30 \%$ performed low physical activity. Tobacco and alcohol intake was prevalent in 29.3\% and 21.0\% respectively. High CVD risk ratio was found in $14.3 \%$. Most risk factors were more prevalent among juniors except diabetes. Among the nonoverweight and non-obese subjects there was a significant positive correlation between WHtR and CVD risk score $(R=0.33, p<0.001) .82 .7 \%$ of the variance in CVD risk ratio could be explained by WHtR, Body mass index, Triglycerides and Low-density lipoprotein $(F(7,425)=296.085)$, of which $\operatorname{LL}(\beta=0.755)$ contributed the most.

Conclusions: High prevalence of different modifiable CVD risk factors revealed among the subjects in this study is concerning. WHtR appears promising as an independent early predictor of CVD risk in Indian population. A dedicated CVD risk assessment tool for the young population is necessary.

Keywords: Cardiovascular disease risk, MBBS students, Waist-to-height ratio, Young population

\section{Background}

Cardiovascular diseases (CVDs) lead the causes of morbidity and mortality worldwide and more than $75 \%$ of Cardiovascular diseases related deaths occurs in low- and

\footnotetext{
*Correspondence: anindya768@yahoo.co.in

†'Somnath Mukhopadhay and Anindya Mukherjee contributed equally to this work and are joint first authors

2 Department of Cardiology, NRS Medical College, 138, A.J.C. Bose Road, Kolkata 700014 , India

Full list of author information is available at the end of the article
}

middle-income countries $[1,2]$. It is the leading cause of death in India and Cardiovascular diseases deaths occur a decade earlier in Indians than Western countries [3, 4].

Atherogenic diet, sedentary lifestyle and 'South Asian lipid profile' are the most important behavioural risk factors for insulin resistance which leads to metabolic syndrome, diabetes mellitus, obesity and eventually Cardiovascular diseases [5].

Long term Cardiovascular diseases risk in young adults can be strongly predicted by their risk factor profiles [6]. 
The magnitude and types of risk factors among young adults needs to be understood to establish targeted intervention through lifestyle changes [6, 7]. Most of the young adults are not aware of the Cardiovascular diseases risk and do not undergo screening leading to risk underestimation in spite of high prevalence [6]. Hence, the urgent need of addressing the prevalence of Cardiovascular diseases risk factors among young adults.

Undergraduate medical students form a very important subset of young adults in any society since they are the forming elements of the future healthcare infrastructure. The stress associated with intense training in medical school and lack of physical exercise puts the students at higher risk of Cardiovascular diseases [8]. Various studies have shown the high prevalence of Cardiovascular diseases risk factors among medical or nursing students [812]. The awareness levels of medical students regarding Cardiovascular diseases risk factors needs further insight and improvement $[13,14]$. In India there has been only handful studies reporting the prevalence of Cardiovascular diseases risk factors among medical students and none from the eastern part of the country [8-10]. Prevalence of Cardiovascular diseases risk factors vary across ethnicity and races [14].

The objective of the current study was to estimate the prevalence of risk factors of Cardiovascular diseases and their association with Cardiovascular diseases risk ratio among the undergraduate medical students of a tertiary care facility of eastern India.

\section{Methods}

\section{Subjects/study design}

The study employed the descriptive, cross-sectional approach. Undergraduate medical students pursuing Bachelor of Medicine, Bachelor of Surgery (MBBS) course, who did not have known cardiovascular diseases, were recruited from 1 May 2019 to 31 July 2020. The students in 1st and 2nd year of their MBBS curriculum have been referred to as the junior students and those in 3rd and final years as senior students in the following text. Purposive sample size was calculated to be $\geq 385$ to have confidence level of $95 \%$ so that the real values were within $\pm 5 \%$ of measured or surveyed value [15]. All procedures followed were in accordance with the ethical standards of the responsible committee on human experimentation (institutional and national) and with the Helsinki Declaration of 1964 and later revisions. Informed written consent was obtained from all subjects for being included in the study.

\section{Questionnaire}

An anonymous, confidential, self-administered structured questionnaire was used which included their age, gender, year of education, family history of Cardiovascular diseases, tobacco intake and alcohol use. Tobacco intake or alcohol use was defined as history of regular or occasional tobacco or alcohol use respectively [16]. Urban and rural residence was defined as per the Indian census guidelines [17]. Family history of Cardiovascular diseases was defined as a self-reported diagnosis of Cardiovascular diseases in parents, siblings, or children that occurred at 60 years or younger [18]. Apart from these, 2 pre-validated questionnaires were included in the structured questionnaire- International Physical Activity Questionnaire (IPAQ)-Long form for assessment of physical activity and Perceived Stress Scale (PSS) to elicit psychological stress levels $[19,20]$. Physical activity was classified as low, moderate and high as per International Physical Activity Questionnaire (IPAQ)-Long form. Scores ranging from 0 to 13 in physical activity and Perceived Stress Scale (PSS) were considered low stress, 14-26 were considered moderate stress and 27-40 were considered high perceived stress.

\section{Anthropometric measurements}

Body weights were measured with the HBF-516 Body Composition Monitor and Scale (IL, USA). Waist circumference was measured at the midpoint between last rib and iliac crest [21]. SecaStadiometer (Hamburg, Germany) was used to measure the heights to the nearest $0.1 \mathrm{~cm}$. Waist-to-height ratio (WHtR) was calculated and a boundary value of 0.5 was used [22]. Body mass index was calculated from height and weight with following categorization: Underweight $\left(<18.0 \mathrm{~kg} / \mathrm{m}^{2}\right)$, normal body mass index $\left(18.0-22.9 \mathrm{~kg} / \mathrm{m}^{2}\right)$, overweight $(23.0-24.9 \mathrm{~kg} /$ $\left.\mathrm{m}^{2}\right)$, obese $\left(>25 \mathrm{~kg} / \mathrm{m}^{2}\right)[23]$.

\section{Blood pressure, glucose and lipid profile}

The subjects sat in a relaxed and comfortable position and all measurements were taken on the right arm with Omron digital blood pressure monitor (IL, USA). 2018 European Society of Cardiology (ESC) hypertension guidelines were followed in measuring and categorizing blood pressure thus defining hypertension as systolic blood pressure (SBP) $\geq 140 \mathrm{~mm} \mathrm{Hg}$ and/or diastolic blood pressure (DBP) $\geq 90 \mathrm{~mm} \mathrm{Hg} \mathrm{[24].}$

$3 \mathrm{~mL}$ of venous blood was collected into gel separator tubes for lipid profiling after $12 \mathrm{~h}$ of fasting. After centrifugation at 3000 rotation per minute for $10 \mathrm{~min}$, the serum samples were used for analysis by Vitros 5-IFS chemistry analyzer (NY, USA). The amount of low-density lipoprotein cholesterol (LDL) in each serum was obtained using the Friedewald's equation: low-density lipoprotein cholesterol $(\mathrm{LDL})=$ Total cholesterol $(\mathrm{TC})$-highdensity lipoprotein cholesterol (HDL-C) - (Triglyceride [TG]/2.2) [25]. The ranges (in $\mathrm{mg} / \mathrm{dL}$ ) were categorized as follows: Triglyceride $<150$ - acceptable, $\geq 150$ - high; 
Total cholesterol $<200$ - acceptable, $\geq 200$ - high; low-density lipoprotein cholesterol $\leq 100$ - acceptable, $>100$ - high; and high-density lipoprotein cholesterol $\leq 40$ (men)low, $>40$ (men)- acceptable, $\leq 50$ (women)- low, $>50$ (women)- acceptable [21]. Total cholesterol to highdensity lipoprotein cholesterol ratio was calculated as the cardiovascular diseases risk ratio and categorized as $\leq 4.5$ (men)-acceptable, $>4.5 \quad$ (men)- high, $\leq 4.0 \quad$ (women)acceptable, $>4.0$ (women)-high [26].

Diabetes was defined as fasting plasma glucose $(\mathrm{FPG}) \geq 126 \mathrm{mg} / \mathrm{dL}$ where fasting was defined as no caloric intake for at least $8 \mathrm{~h}$. In the absence of unequivocal hyperglycemia, diagnosis was done based on two abnormal test results from the same sample or two separate test samples [27].

\section{Data analysis}

Statistical package for Social Science (SPSS) version 25 (SPSS Inc, Chicago, Ill., USA) was used to analyse the data. Mean and standard deviation (SD) for continuous variables and percentages for categorical variables were calculated as part of descriptive analysis. Continuous variables were compared by Student's t test while categorical variables were compared by Chi-square test. A p value of less than 0.05 was considered statistically significant. Associations were assessed using Chi-Square tests of association. Correlation between the cardiovascular risk factors was assessed by Pearson's correlations. Multiple linear regressions were used to assess the extent of independent contribution of variables to the development of Cardiovascular diseases risk.

\section{Results}

Baseline characteristics

433 undergraduate medical students were included of whom 263 were men and 170 were women. $68.6 \%$ of the subjects were in junior classes. $62.1 \%$ students belonged to urban population. Mean Triglyceride, Total cholesterol, low-density lipoprotein, waist circumference, diastolic blood pressure and cardiovascular risk ratio were significantly higher in men; mean high density lipoprotein was significantly lower in men. Baseline characteristics have been outlined in Table 1. 21.2\% were hypertensive and $13.4 \%$ were diabetic. None of the students were married or on oral contraceptive pills.

\section{Cardiovascular diseases risk prevalence Gender wise prevalence}

Significantly higher proportion of men (25.9\%) had high perceived Stress Scale (PSS) than women (17.1\%) ( $p$ 0.03). Approximately $30 \%$ of both men and women had low physical activity while none in the study reported of high physical activity. Tobacco and alcohol intake was significantly higher in men (39.2\% and $31.6 \%$ respectively) than women $(p<0.001)$. High low-density lipoprotein (35.4\%), triglyceride (39.2\%) and total cholesterol (25.1\%) were significantly more frequent in men while low highdensity lipoprotein was significantly more frequent in women $(30 \%)(p<0.005)$. Diabetes was more prevalent among men $(p=0.01)$. High cardiovascular disease risk ratio was found to be significantly more common in men $(19 \%)(p<0.001)$. The gender wise prevalence is outlined

Table 1 Background characteristics of students

\begin{tabular}{|c|c|c|c|c|}
\hline Variable & Male $(n=263)$ & Female $(n=170)$ & Total $(n=433)$ & Significance \\
\hline Age (years) & $22.5 \pm 1.9$ & $21.8 \pm 2.2$ & $22.2 \pm 2.1$ & $0.001^{*}$ \\
\hline Junior & $197(74.9)$ & $100(58.8)$ & 297 (68.6) & $0.001^{*}$ \\
\hline Senior & $66(25.1)$ & $70(41.2)$ & $136(31.4)$ & \\
\hline Urban & $152(57.8)$ & $117(68.8)$ & $269(62.1)$ & $0.02^{*}$ \\
\hline Rural & $111(42.2)$ & $53(31.2)$ & $164(37.9)$ & \\
\hline $\mathrm{BMI}\left(\mathrm{kg} / \mathrm{m}^{2}\right)$ & $25.5 \pm 3.9$ & $25.5 \pm 3.7$ & $25.5 \pm 3.9$ & 0.9 \\
\hline $\mathrm{TG}(\mathrm{mg} / \mathrm{dL})$ & $147.7 \pm 74.6$ & $125.8 \pm 59.0$ & $139.1 \pm 36.7$ & $0.001^{*}$ \\
\hline $\mathrm{TC}(\mathrm{mg} / \mathrm{dL})$ & $174.0 \pm 39.5$ & $162.2 \pm 30.6$ & $169.3 \pm 36.7$ & $0.001^{*}$ \\
\hline $\mathrm{HDL}(\mathrm{mg} / \mathrm{dL})$ & $51.7 \pm 9.9$ & $54.8 \pm 9.4$ & $52.9 \pm 9.8$ & $0.001^{*}$ \\
\hline LDL (mg/dL) & $92.8 \pm 34.7$ & $82.2 \pm 26.1$ & $88.6 \pm 32.0$ & $0.001^{*}$ \\
\hline FPG (mg/dL) & $98.0 \pm 23.8$ & $97.4 \pm 20.7$ & $97.8 \pm 22.6$ & 0.8 \\
\hline WHtR & $0.48 \pm 0.05$ & $0.49 \pm 0.05$ & $0.49 \pm 0.05$ & $0.02^{*}$ \\
\hline $\mathrm{SBP}(\mathrm{mmHg})$ & $127.3 \pm 12.6$ & $126.0 \pm 12.5$ & $126.8 \pm 12.6$ & 0.3 \\
\hline $\mathrm{DBP}(\mathrm{mmHg})$ & $82.2 \pm 7.3$ & $78.6 \pm 6.7$ & $80.8 \pm 7.3$ & $<0.001^{*}$ \\
\hline Cardiovascular risk ratio & $3.5 \pm 1.1$ & $3.1 \pm 0.8$ & $3.3 \pm 1.0$ & $<0.001^{*}$ \\
\hline
\end{tabular}

BMI, body mass index; DBP, diastolic blood pressure; FPG, fasting plasma glucose; HDL, high density lipoprotein; LDL, low density lipoprotein; SBP, systolic blood pressure; TC, total cholesterol; TG, triglyceride

*Test significant at $p<0.05$. Continuous variables are expressed as mean $\pm \mathrm{SD}$ (corrected up to 1st decimal) and discrete variables are expressed as $n$ (\%) 
High CVD risk ratio $(p<0.001)$

Low HDL $(p<0.001)$

High TC $(p<0.001)$

High TG $(p=0.004)$

High LDL $(p=0.001)$

High WHtR ( $p=0.051)$

Diabetes $(p=0.01)$

Hypertension $(p=0.3)$

Overweight and obese $(p=0.7)$

Tobacco intake $(p<0.001)$

$F / H$ of CVD $(p=0.2)$

Low Physical activity $(p=0.7)$

High PSS $(p=0.03)$

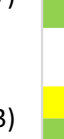

$0 \%$

\section{$7.1 \%$}

$19 \%$

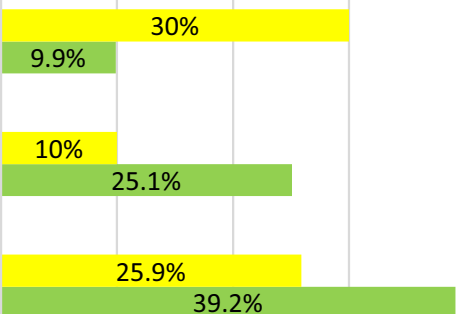

$39.2 \%$
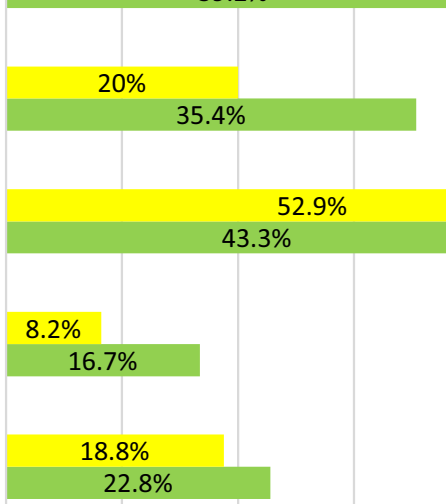

$3.3 \%$

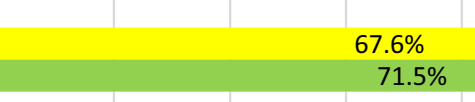

$71.5 \%$
$14.1 \%$

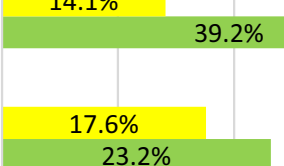

$23.2 \%$

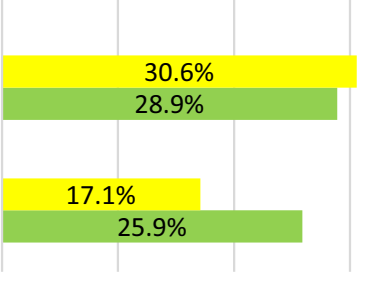

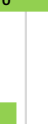

Women $(n=170) \quad$ Men $(n=263)$

Fig. 1 CVD risk factor prevalence among male and female students

in Fig. 1 and detailed gender wise distribution is tabulated in Additional file 1: Table S1.

\section{Seniority wise prevalence}

High Perceived Stress Scale (27.3\%), low physical activity (36.4\%), F/H of diabetes mellitus (DM) (33.7\%), tobacco intake $(35.4 \%)$, alcohol intake $(24.9 \%)$, overweight (20.9\%), obesity (57.2\%) was significantly more common among juniors $(p<0.05)$. Diabetes was more prevalent among seniors $(p=0.001)$. Similarly, increased waist-height ratio (WHtR) (52.9\%), high low-density lipoprotein (33\%), high triglyceride (38\%), high total cholesterol (22.6\%) were significantly more common among junior students $(p<0.05)$. The seniority wise prevalence is outlined in Fig. 2 and detailed 
seniority wise distribution is tabulated in Additional file 1: Table S2.

\section{Association and correlation}

Male gender, high PSS, low physical activity, tobacco intake, overweight and obesity, hypertension, diabetes, high waist-height ratio (WHtR), high triglyceride and high low-density lipoprotein had significant association with high cardiovascular disease risk ratio as outlined in Fig. 3. Additional file 1: Table S3 details the statistics of this analysis.

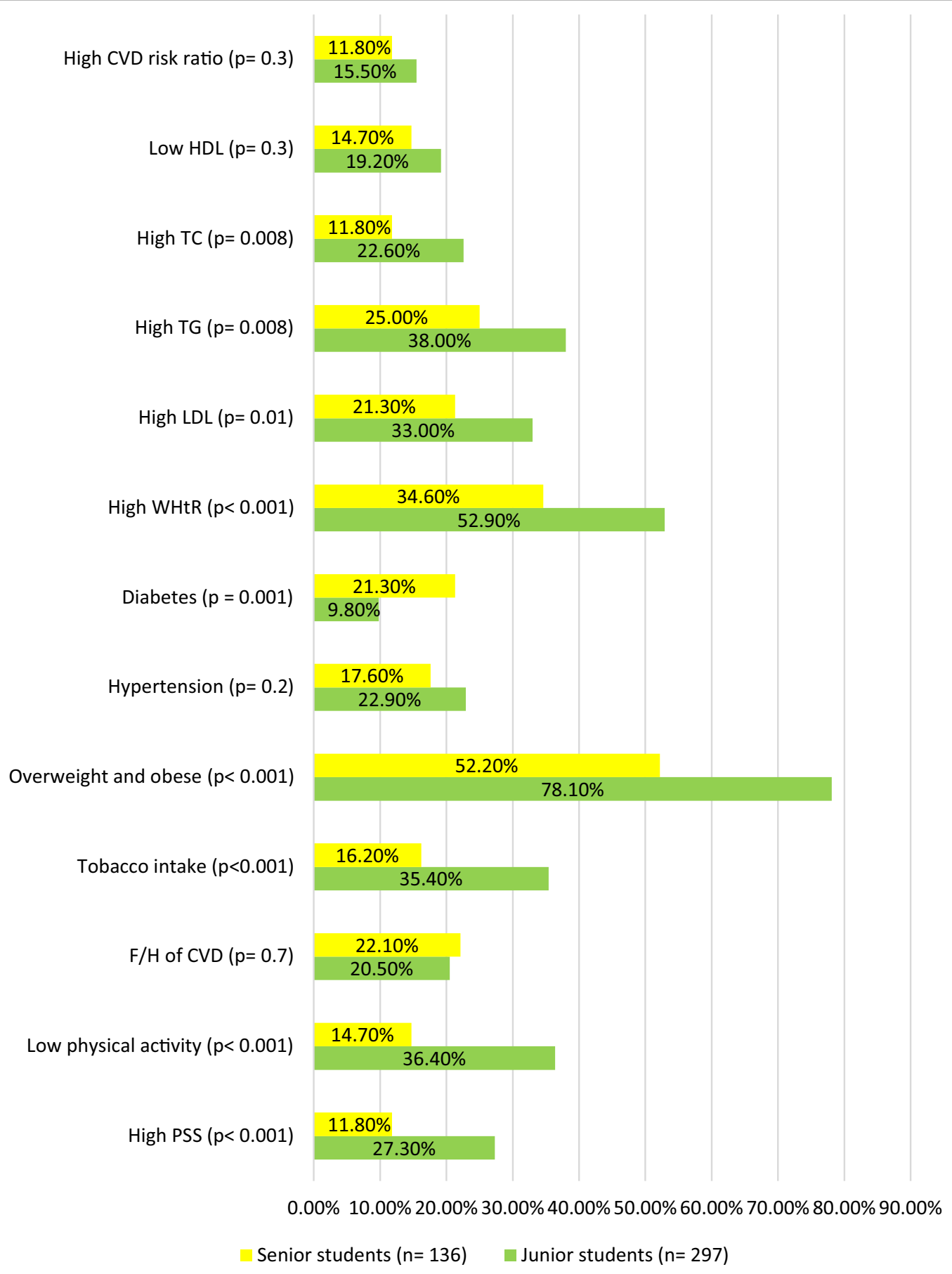

Fig. 2 Cardiovascular risk factor prevalence among junior students and senior students 
Waist-height ratio and cardiovascular risk score was weakly correlated with Pearsons's $R=0.19(p<0.001)$ across overall population. Among overweight and obese subjects there was no significant correlation $(p=0.6)$ while among the non-overweight and non-obese subjects there was a weak but significant positive correlation $(R=0.33, p<0.001)$ as depicted in Fig. 4 .

\section{Discussion}

The INTERHEART and INTERSTROKE study defined the impact of the 9 potentially modifiable risk factors (diabetes, hypertension, smoking, lipids, obesity, diet, physical activity, alcohol consumption and psychosocial factors) on cardiovascular disease and thus the approach to prevention of the same $[28,29]$. Our study aimed to assess the cardiovascular disease risk factors among the undergraduate medical students from a tertiary centre of eastern India. Being the first study from this part of the country, this sheds light on the risk factors among medical students that needs to be intervened upon to improve the quality of life of future doctors. Comparison of the data with other recent studies conducted on medical students in different parts India have been discussed in Table 2.

\section{Stress}

High perceived Stress Scale was noted in $22.4 \%$ of the subjects in this study. The study by Khan AAA et al. found stress to be present in $25.5 \%$ medical students and sadness or depression in $3.0 \%$. Stress was detected in $22.5 \%$ of the Indian urban affluent adults aged 30-45 years in the study by Aeri et al. [32]. The medical students were having similar stress levels at a lesser age which is concerning. Similarly, a Portuguese study found extremely high levels of stress in $20.8 \%$ of sixth year medical students and a study from Kingdom

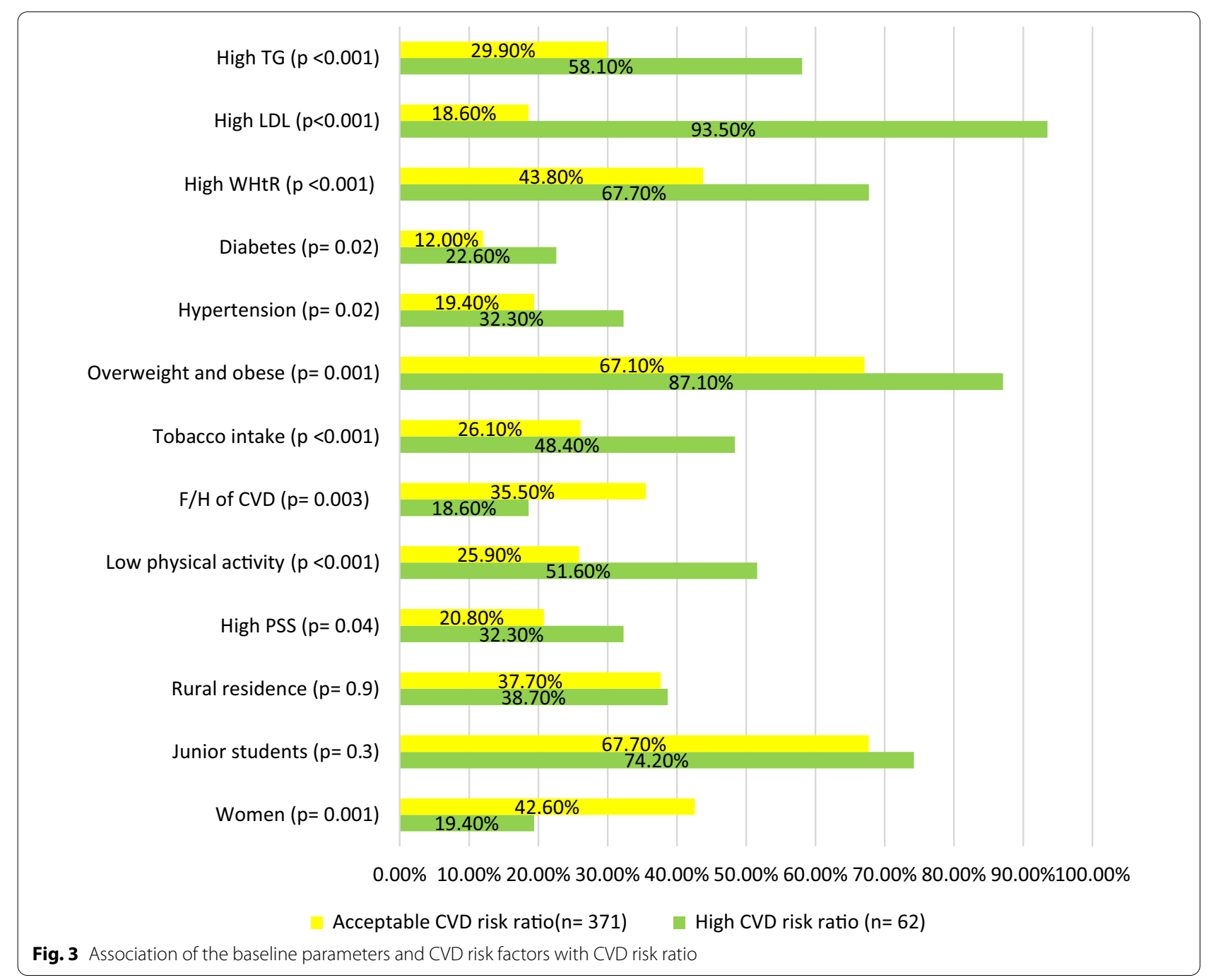




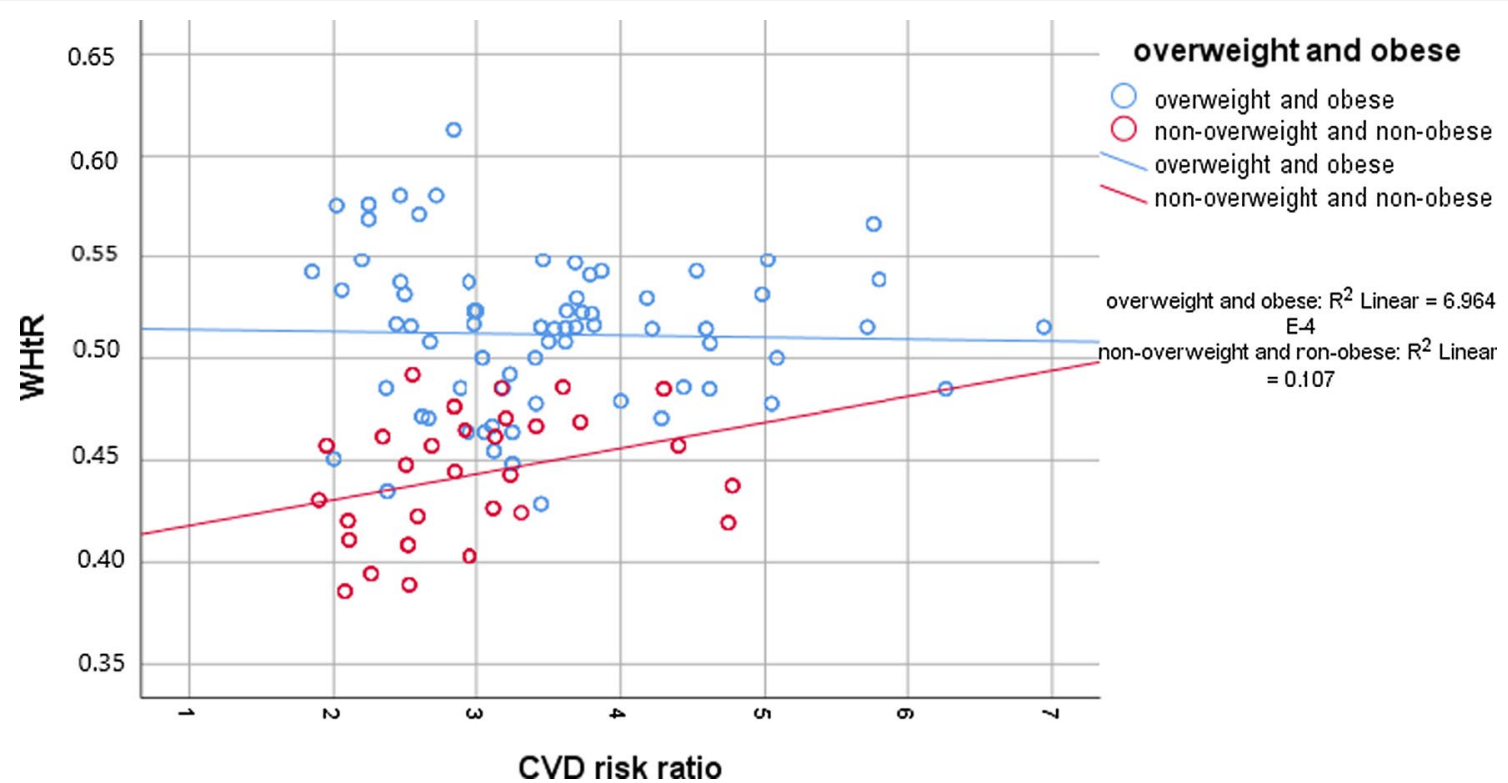

Fig. 4 Correlation between WHtR and CVD risk ratio stratified by overweight and obesity

Table 2 Prevalence of CVD risk factors among medical students in different studies from India

\begin{tabular}{|c|c|c|c|c|c|c|}
\hline Study & $\begin{array}{l}\text { Mukhopadhay } \\
\text { et al. (2021) }\end{array}$ & Rustagi et al. [30] & Paul B et al. [9] & Kurian et al. [31] & Nanjesh et al. [10] & Ameer Khan et al. [8] \\
\hline Sample size & 433 & 433 & 458 & 144 & 500 & 396 \\
\hline Grades & Undergraduate & Undergraduate & Undergraduate & Undergraduate & Undergraduate & - \\
\hline Site & East India & North India & South India & South India & South India & South India \\
\hline F/H of CVD (\%) & 21.0 & - & 64.2 & 12.0 & 14.2 & 8.1 \\
\hline Tobacco intake (\%) & 29.3 & 7.0 & 5.0 & 0.0 & 11.6 & 4.0 \\
\hline Alcohol intake (\%) & 21.0 & 28.8 & 5.9 & 0.0 & 27.0 & - \\
\hline Low physical activity (\%) & 29.6 & 42.6 & 47.6 & 13.0 & 18.0 & 13.6 \\
\hline Overweight (\%) & 16.4 & - & $38.2^{b}$ & 15.0 & 29.0 & - \\
\hline Obese (\%) & 53.6 & - & & 12.0 & 5.8 & \\
\hline High SBP (\%) & 18.5 & - & $27.1^{\mathrm{a}}$ & 10.0 & $1.2^{\mathrm{a}}$ & $2.0^{\mathrm{a}}$ \\
\hline High DBP (\%) & 13.9 & - & & 21.0 & & \\
\hline $\begin{array}{l}\text { Increased waist circumfer- } \\
\text { ence (\%) }\end{array}$ & 26.1 & - & - & 23.0 & 15.2 & - \\
\hline High LDL (\%) & 29.3 & - & - & 5.0 & - & - \\
\hline High TG (\%) & 33.9 & - & - & 13.0 & - & - \\
\hline High TC (\%) & 19.2 & - & - & 8.0 & - & - \\
\hline Low HDL (\%) & 17.8 & - & - & 33.0 & - & - \\
\hline High CVD risk ratio (\%) & 14.3 & - & - & 16.0 & - & - \\
\hline
\end{tabular}

DBP, diastolic blood pressure; CVD, cardiovascular disease; HDL, high density lipoprotein; LDL, low density lipoprotein; SBP, systolic blood pressure; TC, total cholesterol; TG, triglyceride

a Included all high BP

${ }^{\mathrm{b}}$ Included overweight and obese

of Saudi Arabia reported severe stress in $21.8 \%$ of the female medical students [33, 34]. High perceived Stress Scale was noted in significantly more proportion of junior students which can be due to the more sedentary lifestyle, computer-based classes and being away from home in the pandemic and the stress of the medical curriculum which the senior students get used to with passing years of education. 


\section{Physical activity}

$29.6 \%$ of the students in this study had low physical activity. Physical activity was nil or occasional among $42.6 \%$ subjects in the study by Rustagi et al. [33]. Paul B et al. also reported sedentary activity more than $4 \mathrm{~h}$ per day in $47.6 \%$ of the students [9]. Paul B also found men to be more active than women but in our study there was no significant gender based difference [9]. In contrary, number of subjects performing low total physical activity was lower in the study by Kurian S et al. (13.0\%), Nanjesh SK et al. (18.0) and Thomas A et al. (13.6\%) [8, 10, 31]. Low physical activity has been reported among university students $(22-62 \%)$ from other studies as well [30]. Ibrahim et al. reported physical inactivity in $57.9 \%$ of the medical students in King Abdulaziz University, Jeddah, Saudi Arabia whereas the study by Boo NY from Malaysia reported physical inactivity in $29.9 \%$ of the medical students which was similar to our study population [11, 35]. This can be due to the busy academic schedules of students and overall inclination towards sedentary habits and technology-based lifestyle. In this study junior students were more inclined towards lower physical activity probably because of their computer-based classes in the covid pandemic and lack of clinical ward round based classes in junior years.

\section{Family history}

Family history of cardiovascular disease was present in $21 \%$ of the subjects. Family history of dyslipidemia and diabetes was also prevalent in $21.5 \%$ and $30.0 \%$ students respectively, these nearly similar proportions reflecting the fact that dyslipdemia, diabetes and cardiovascular disease are closely related and goes hand in hand. Family history of cardiovascular disease varied widely across the different studies done across the Indian subcontinent from $64.2 \%$ in the study by Paul B et al. to $8.1 \%$ in the study by Thomas A et al., $14.2 \%$ in the study by Nanjesh SK et al. and $12.0 \%$ in that by Kurian et al. [8-10, 31]. 56.8\% of medical students from a medical college in Karachi were reported to have family history of cardiovascular disease whereas the prevalence of family history of premature coronary artery disease was $14.4 \%$ in Saudi Arabian medical students and 6.7\% in Egyptian medical students in another study $[36,37]$. This variation can be due to socio-demographic differences across the populations.

\section{Tobacco and alcohol intake}

$29.3 \%$ of the students were tobacco users which was significantly higher than the values reported in other Indian studies but similar to the data from 2 studies among Egyptian and Saudi Arabian students where smoking was practiced by $29.7 \%$.and Croatian medical students where $30.4 \%$ were smokers [8-10, 13, 30, 37]. Smoking was noted in $4.9 \%$ of medical students from International Medical University, Malaysia and 2.8\% among students of King Abdulaziz University, Jeddah, Saudi Arabia [11, 35]. This variation can be due to absence of strict non-smoking laws or awareness programs in the institution.

Alcohol intake was prevalent in $21.0 \%$ of the subjects which was nearly similar to the studies by Rustagi $\mathrm{N}$ et al. (28.8\%) and Nanjesh SK et al. (27.0\%) [10,30]. Paul B et al. reported significantly lower values (5.0\%) which can be due to social norms prevalent in that part of the country [9].

Intake of tobacco and alcohol were significantly more prevalent among men similar to other Indian data [10]. But contrary to the study from coastal city of Karnataka, tobacco and alcohol use was more prevalent among junior students in this study, which can be due to the lack of awareness and more sedentary lifestyle.

\section{Overweight, obesity and increased Waist-to-height ratio}

Most of the students were overweight or obese in this study (70\%) with the proportion being more in junior students $(78.1 \%)$ which must be due to the sedentary habits, altered food habits in hostel, alcohol consumption and the covid pandemic induced alteration in lifestyle. Overweight and obesity were prevalent in medical students in other studies across the world as well (25-38\%) but such high proportions are only reported by the studies by Mahmoud AE et al. and Ofori EK et al. where obesity was prevalent in $61.6 \%$ of the Saudi Arabian students and overweight or obesity were prevalent in $53.4 \%$ of students from Ghana respectively [9-12, 31, 35, 37].

Increased waist circumference was noted in $26.1 \%$ of the subjects, more prevalent in juniors (29.6\%) which was higher than $23.0 \%$ reported from central Kerala and $15.2 \%$ from coastal city of Karnataka, reason probably being same as discussed above $[10,31]$.

Unlike the other studies among medical students from India or abroad, this study analysed the Waist-to-height ratio and found it to correlate significantly with cardiovascular disease risk ratio, the strength of correlation increasing slightly when applied among non-overweight and non-obese subjects. As pointed out by Ashwell et al., high Waist-to-height ratio in subjects with "healthy" body mass index can be an indicator of 'early health risk [22]. Hence the use of Waist-to-height ratio even in medical students with normal body mass index can be an early marker of high cardiovascular disease risk.

While overweight and obesity were slightly more prevalent among men, increased waist circumference was significantly more prevalent among women in this study. 


\section{Blood pressure}

High systolic blood pressure and diastolic blood pressure were noted in $18.5 \%$ and $13.9 \%$ subjects respectively. While high systolic blood pressure had nonsignificant gender-wise or seniority wise difference in prevalence, high diastolic blood pressure was significantly more common among men and juniors $(66.3 \%$ of the juniors were men). This difference can be attributed to more smoking and alcohol consumption in men. The prevalence was similar to those found in studies by Paul B et al. and Kurian S et al. whereas, Nanjesh SK et al. and Thomas A et al. found negligible proportion subjects with high blood pressure [8-10, 31]. Ibrahim NK et al. found high systolic and high diastolic blood pressures in 3.7\% and 7.9\% of the Saudi Arabian students, on the other hand Ofori EK et al. noted high systolic and high diastolic blood pressures in $45 \%$ and $32.5 \%$ of the students from Ghana [11]. These wide variations can be attributed to the socio-cultural and genetic differences across the different populations and needs to be taken into consideration while planning preventive and curative strategies.

\section{Lipid profile}

High low-density lipoprotein was observed in $29.3 \%$ subjects, high triglyceride in $33.9 \%$, High total cholesterol in $19.2 \%$ which were also more prevalent in men and among junior students may be because bulk of junior students included in the study were men as discussed earlier. Low high-density lipoprotein was prevalent in $17.8 \%$ with female predominance. Hypercholesterolemia was present in $17.2 \%$ of the students in King Abdulaziz University, Jeddah, Saudi Arabia while dyslipidemia was reported to be present in $6.1 \%$ in another study on Egyptian and Saudi Arabian medical students [11, 37]. Triglycerides, total cholesterol and low-density lipoprotein were high in $4.2 \%, 30 \%$ and $67.5 \%$ of the nursing students from Ghana while high-density lipoprotein was low in 32.5\% [12]. The study by Kurian $\mathrm{S}$ et al. found the prevalence of high low-density lipoprotein, triglyceride and total cholesterol to be $5.0 \%, 13.0 \%$ and $8 \%$ while prevalence of low highdensity lipoprotein was more than this study (33.0\%) [31]. The difference of low high density lipoprotein may be due to genetic difference, while the lower low density lipoprotein, triglyceride, total cholesterol can be attributed to lesser prevalence of family history of cardiovascular disease, no intake of tobacco or alcohol and better physical activity profile in the study populations. Covid pandemic induced lifestyle changes may have also attributed to the increased prevalence of higher lipid parameters in the current study.

Prevalence of high cardiovascular disease risk ratio did not differ between the two studies probably because of the higher prevalence of low high-density lipoprotein in the study from central Kerala [30]. Prevalence of high cardiovascular disease risk ratio was also similar to the study from Ghana [12].

\section{Comparison with general population}

In the current study prevalence of high systolic blood pressure and diastolic blood pressure were noted in $18.5 \%$ and $13.9 \%$ subjects respectively with $5.5 \%$ subjects being known hypertensives. $13.4 \%$ subjects had high FPG, 4.4\% were known type 2 diabetics and 1 was type 1 diabetic. $29.3 \%$ were tobacco users. High lowdensity lipoprotein, triglyceride, total cholesterol and low high density lipoprotein were noted in $29.3 \%, 33.9 \%$, $19.2 \%$ and $17.8 \%$ respectively and $12.9 \%$ had known dyslipidemia. Large prevalence studies from Indian adults found hypertension to be prevalent in 10.6-39.0\%, diabetes to be prevalent in $1.5 \%-21.0 \%$, high cholesterol to be present in $23.0-54.1 \%$, smoking in $18.1-42.0 \%$ [38].

\section{Correlation between risk factors}

In this study, correlation was noted between body mass index, waist to height ratio, triglyceride, low density lipoprotein and cardiovascular disease risk ratio. Similarly, Ofori EK et al. found strong correlations between low density lipoprotein and CVD risk ratio and moderate correlation between total cholesterol and cardiovascular disease risk ratio [12].

\section{Limitations}

Modification of QRISK2 including smokeless tobacco has been proven to be an important tool for cardiovascular disease risk stratification among Indians but the age group in QRISK 2 and QRISK 3 is 25-84 years [39, 40]. The age group for another important tool, Framinham Risk Score is 30-79 years while for Pooled cohort equation is $40-79$ years $[41,42]$. Berry et al. demonstrated that Framinham Risk score and ATP III risk score failed to work in individuals younger than 30 years [42]. Thus total cholesterol/high density lipoprotein ratio was chosen as cardiovascular disease risk ratio as it has been proven to be useful as cardiovascular disease risk estimator and it was easy to use [25]. But multifactorial assessment of cardiovascular disease risk has been compromised due to the inability to use the newer risk scores.

Another major limitation of the study was the comparison between two generation of students. Evaluation of the same population from junior to senior levels would have given clearer conclusion about the success of medical education and development of awareness. Multi-centre based prospective study including larger sample size comprising of undergraduates, interns, postgraduates would give a clearer idea regarding the cardiovascular disease risk factors among medical 
students in Indian subcontinent. One has to keep in mind that medical undergraduates may not represent the general youth. Covid-19 pandemic scenario may have affected the physical activity and mental stress of the students. Food habits, Lipoprotein (a), High sensitivity C-reactive protein, homocysteine, hemoglobin A1C, uric acid was not included in analysis.

\section{Conclusions}

High prevalence of different modifiable cardiovascular disease risk factors revealed among the subjects in this study is concerning and needs implementation of screening programs, awareness initiatives and surveillance activities. Medical core curriculum should be modified in the direction of awareness and prevention. Regulatory and legislative actions for in-campus tobacco and alcohol use are required. Further research is warranted for the assessment of waist to height ratio (WHtR) as an independent early predictor of cardiovascular disease risk in Indian population and development of a cardiovascular disease risk assessment tool for the young population, given the steep rise of cardiovascular disease in young population across the globe.

\section{Abbreviations}

BMI: Body mass index; DBP: Diastolic blood pressure; FPG: Fasting plasma glucose; HDL: High-density lipoprotein; LDL: Low-density lipoprotein; SBP: Systolic blood pressure; TC: Total cholesterol; TG: Triglyceride; WHtR: Waist-toheight ratio; CVD: Cardiovascular disease; F/H: Family history; PSS: Perceived stress scale.

\section{Supplementary Information}

The online version contains supplementary material available at https://doi. org/10.1186/s43044-021-00219-9.

Additional file 1: Table S1. Gender-wise comparison of cardiovascular risk factors prevalence among students. Table S2. Comparison of cardiovascular risk factors prevalence among junior students and senior students. Table S3. Association of the baseline parameters with CVD risk ratio

\section{Acknowledgements}

None.

\section{Authors' contributions}

SG: Concept and design; SM, AM, BS, AK: acquisition of data; AM, DK, BS: interpretation of data, drafting the article; SM, AM, DK, BS, AK, SG: critical review and final approval of the study. All authors have read and approved the manuscript.

\section{Funding}

None.

\section{Availability of data and materials}

Available when requested.

\section{Declarations}

Ethical approval and consent to participate

The ethical standards of the responsible committee on human experimentation (institutional and national) and the Helsinki Declaration of 1964 and later revisions were followed in all steps of research. All the subjects gave written informed consent for the study. Institutional Review Board approved the study. Study approved by institutional ethical committee of Medical College and Hospital, Kolkata, reference number not applicable. No subject was less than 16 years old, deceased, or unconscious in the study.

\section{Consent to publication}

All the subjects gave written informed consent for the study.

\section{Competing interests}

The authors declare that they have no competing interests.

\section{Author details}

${ }^{1}$ Asansol District Hospital, Asansol, India. ${ }^{2}$ Department of Cardiology, NRS Medical College, 138, A.J.C. Bose Road, Kolkata 700014, India. ${ }^{3}$ Royal Wolverhampton NHS Trust, Wolverhampton, UK. ${ }^{4}$ Department of Cardiology, Medical College, Kolkata, India. ${ }^{5}$ Department of Cardiology, AMRI Hospitals, Kolkata, India. ${ }^{6}$ Department of Cardiology, Ruby General Hospital, Kolkata, India.

Received: 23 June 2021 Accepted: 16 October 2021

Published online: 26 October 2021

\section{References}

1. Boutayeb A (2006) The double burden of communicable and non-communicable diseases in developing countries. Trans R Soc Trop Med Hyg 100(3):191-199. https://doi.org/10.1016/j.trstmh.2005.07.021

2. Cardiovascular diseases (CVDs) [Internet]. Who.int. [cited 2021 May 24]. Available from: https://www.who.int/en/news-room/fact-sheets/detail/ cardiovascular-diseases-(cvds)

3. CDC in India [Internet]. Cdc.gov. 2021 [cited 2021 May 24]. Available from: https://www.cdc.gov/globalhealth/countries/india/default.htm

4. Joshi P, Islam S, Pais P, Reddy S, Dorairaj P, Kazmi K, Pandey MR, Haque S, Mendis S, Rangarajan S, Yusuf S (2007) Risk factors for early myocardial infarction in South Asians compared with individuals in other countries. JAMA 297(3):286-294. https://doi.org/10.1001/jama.297.3.286

5. Puri R, Iyengar S, Narasingan SN (2016) Lipid association of India expert consensus statement on management of dyslipidemia in Indians 2016: Part 1-executive summary. J Clin Prev Cardiol 5(2):51

6. Arts J, Fernandez ML, Lofgren IE (2014) Coronary heart disease risk factors in college students. Adv Nutr 5(2):177-187. https://doi.org/10.3945/an. 113.005447

7. Sabra AA, Taha AZ, Al-Sebiany AM, Al-Kurashi NY, Al-Zubier AG (2007) Coronary heart disease risk factors: prevalence and behavior among male university students in Dammam City, Saudi Arabia. J Egypt Public Health Assoc 82(1-2):21-42

8. Thomas A, Ameer Khan A, Muhamed N, Jayaprakash V, Dutt J, Sajeev $S$ (2018) A study on estimating the cardiovascular disease risk among medical students in central Kerala: the INTERHEART method. J Clin Prev Cardiol 7(4):144. https://doi.org/10.4103/jcpc.jcpc_17_18

9. Paul B, Nayaaki V, Sen M, Isaac R (2015) Prevalence of cardiovascular disease risk among medical students in South India. Indian J Commun Health 27(2):211-215

10. Nanjesh KS, Hameed S, Alva ABR, Singh DK, Kurulkar PV, Jayaram S (2016) Study of coronary risk factors among medical students in coastal city of Karnataka. Natl J Commun Med 7(3):171-175

11. Ibrahim NK, Mahnashi M, Al-Dhaheri A, Al-Zahrani B, Al-Wadie E, Aljabri M, Al-Shanketi R, Al-Shehri R, Al-Sayes FM, Bashawri J (2014) Risk factors of coronary heart disease among medical students in King Abdulaziz University, Jeddah. Saudi Arabia BMC Public Health 14(1):411. https://doi.org/ 10.1186/1471-2458-14-411

12. Ofori EK, Intiful FD, Asante M, Asare GA, Adjei PK, Steele-Dadzie RK, Amoako-Mensah A, Mensah D, Angmorterh SK (2018) Prevalence of 
cardiovascular disease risk factors among students of a tertiary institution in Ghana. Food Sci Nutr 6(2):381-387. https://doi.org/10.1002/fsn3.565

13. Reiner Ž, Sonicki Z, Tedeschi-Reiner E (2012) The perception and knowledge of cardiovascular risk factors among medical students. Croat Med J 53(3):278-284. https://doi.org/10.3325/cmj.2012.53.278

14. Maksimović MŽ, Marinković JM, Vlajinac HD, Maksimović JM, Tomanić MS, Radak DJ (2017) Awareness and knowledge of cardiovascular disease risk factors among medical students. Wien Klin Wochenschr 129(13-14):458463. https://doi.org/10.1007/s00508-017-1192-0

15. Calculator.net. [cited 2021 May 24]. Available from: https://www.calcu lator.net/samplesizecalculator.html?type $=1 \& \mathrm{cl}=95 \& \mathrm{ci}=5 \& \mathrm{pp}=50 \& \mathrm{ps}=$ $\& x=97 \& y=23$

16. World Health Organization (WHO) (1998) Guidelines for controlling the tobacco epidemic. World Health Organization, Genève

17. Census of India-census terms [Internet]. Gov.in. [cited 2021 May 24]. Available from: https://censusindia.gov.in/Data_Products/Library/Indian_ perceptive_link/Census_Terms_link/censusterms.html

18. Valerio L, Peters RJ, Zwinderman AH, Pinto-Sietsma S-J (2016) Association of family history with cardiovascular disease in hypertensive individuals in a multiethnic population. J Am Heart Assoc. https://doi.org/10.1161/ JAHA. 116.004260

19. Mehta SP, Jarvis A, Standifer D, Warnimont C (2018) International physical activity questionnaire. Crit Rev Phys Rehabil Med 30(2):125-127. https:// doi.org/10.1615/CritRevPhysRehabilMed.2018026433

20. Cohen S, Kamarck T, Mermelstein R (1983) A global measure of perceived stress. J Health Soc Behav 24(4):385-396

21. Ross R, Neeland IJ, Yamashita S, Shai I, Seidell J, Magni P, Santos RD, Arsenault B, Cuevas A, Hu FB, Griffin BA, Zambon A, Barter P, Fruchart JC, Eckel RH, Matsuzawa Y, Després JP (2020) Waist circumference as a vital sign in clinical practice: a consensus statement from the IAS and ICCR Working Group on Visceral Obesity. Nat Rev Endocrinol 16(3):177-189. https://doi. org/10.1038/s41574-019-0310-7

22. Ashwell M, Gibson S (2016) Waist-to-height ratio as an indicator of "early health risk": simpler and more predictive than using a "matrix" based on BMI and waist circumference. BMJ Open 6(3):e010159. https://doi.org/10. 1136/bmjopen-2015-010159

23. Misra A (2015) Ethnic-specific criteria for classification of body mass index: a perspective for Asian Indians and American Diabetes Association position statement. Diabetes Technol Ther 17(9):667-671. https://doi.org/ 10.1089/dia.2015.0007

24. de Simone G, Dominiczak A, Kahan T, Mahfoud F, Redon J, Ruilope L, Zanchetti A, Kerins M, Kjeldsen SE, Kreutz R, Laurent S, Lip GYH, McManus R, Narkiewicz K, Ruschitzka F, Schmieder RE, Shlyakhto E, Tsioufis C, Aboyans V, Desormais I; Authors/Task Force Members (2018) 2018 ESC/ESH guidelines for the management of arterial hypertension: the task force for the management of arterial hypertension of the European Society of Cardiology and the European Society of Hypertension. J Hypertens 36(10):1953-2041. https://doi.org/10.1097/HJH.0000000000001940

25. Mach F, Baigent C, Catapano AL, Koskinas KC, Casula M, Badimon L, Chapman MJ, De Backer GG, Delgado V, Ference BA, Graham IM, Halliday A, Landmesser U, Mihaylova B, Pedersen TR, Riccardi G, Richter DJ, Sabatine MS, Taskinen MR, Tokgozoglu L, Wiklund O; ESC Scientific Document Group (2020) 2019 ESC/EAS quidelines for the management of dyslipidaemias: lipid modification to reduce cardiovascular risk. Eur Heart J 41(1):111-88. https://doi.org/10.1093/eurheartj/ehz455

26. Millán J, Pintó X, Muñoz A, Zúñiga M, Rubiés-Prat J, Pallardo LF, Masana L, Mangas A, Hernández-Mijares A, González-Santos P, Ascaso JF, Pedro-Botet J (2009) Lipoprotein ratios: physiological significance and clinical usefulness in cardiovascular prevention. Vasc Health Risk Manag 5:757-765

27. American Diabetes Association (2021) Classification and diagnosis of diabetes: standards of medical care in diabetes-2021. Diabetes Care 44(Suppl 1):S15-33. https://doi.org/10.2337/dc21-S002
28. Yusuf S, Hawken S, Ounpuu S, Dans T, Avezum A, Lanas F, McQueen M, Budaj A, Pais P, Varigos J, Lisheng L; INTERHEART Study Investigators (2004) Effect of potentially modifiable risk factors associated with myocardial infarction in 52 countries (the INTERHEART study): case-control study. Lancet 364(9438):937-52. https://doi.org/10.1016/S0140-6736(04) 17018-9

29. O'Donnell MJ, Xavier D, Liu L, Zhang H, Chin SL, Rao-Melacini P, Rangarajan S, Islam S, Pais P, McQueen MJ, Mondo C, Damasceno A, LopezJaramillo P, Hankey GJ, Dans AL, Yusoff K, Truelsen T, Diener HC, Sacco RL, Ryglewicz D, Czlonkowska A, Weimar C, Wang X, Yusuf S; INTERSTROKE investigators (2010) Risk factors for ischaemic and intracerebral haemorrhagic stroke in 22 countries (the INTERSTROKE study): a case-control study. Lancet 376(9735):112-23.https://doi.org/10.1016/S0140-6736(10) 60834-3

30. Rustagi N, Taneja D, Mishra P, Ingle G (2011) Cardiovascular risk behaviour among students of a medical college in Delhi. Indian J Commun Med 36(1):51-53. https://doi.org/10.4103/0970-0218.80794

31. Kurian S, Manjula VD, Annamma ZJ (2015) A study on cardio vascular risk factor profile of medical students in a tertiary care hospital of central Kerala. Natl J Med Res 5(1):11-17

32. Aeri B, Chauhan S (2020) Depression, anxiety, and stress among Indian urban affluent adults. Ind J Soc Psychiatr 36(1):60. https://doi.org/10. 4103/ijsp.ijsp_115_18

33. Oura MJ, Moreira AR, Santos P (2020) Stress among Portuguese medical students: a national cross-sectional study. J Environ Public Health 3(2020):6183757. https://doi.org/10.1155/2020/6183757

34. Rafique N, Al-Asoom LI, Latif R, Al Sunni A, Wasi S (2019) Comparing levels of psychological stress and its inducing factors among medical students. J Taibah Univ Med Sci 14(6):488-494. https://doi.org/10.1016/j.jtumed. 2019.11 .002

35. Boo NY, Chia GJ, Wong LC, Chew RM, Chong W, Loo RC (2010) The prevalence of obesity among clinical students in a Malaysian medical school. Singapore Med J 51(2):126-132

36. Raza S, Sheikh MA, Hussain MF, Siddiqui SE, Muhammad R, Aziz S, Qamar S, Saleem MA, Waki N, Faruqi H, Zia A (2010) Dietary modification, body mass index (BMI), blood pressure (BP) and cardiovascular risk in medical students of a government medical college of Karachi. J Pak Med Assoc 60(11):970-974

37. Mahmoud AE (2015) Prevalence of cardiovascular disease risk factors among Egyptian and Saudi medical students: a comparative study. J Egypt Public Health Assoc 90(1):35-39. https://doi.org/10.1097/01.EPX. $0000460969.93981 . c 2$

38. Krishnan MN (2012) Coronary heart disease and risk factors in India-on the brink of an epidemic? Indian Heart J 64(4):364-367. https://doi.org/ 10.1016/j.ihj.2012.07.001

39. Aggarwal P, Sinha SK, Khanra D, Nath RK, Gujral J, Reddy KK, Mukherjee A (2021) Comparison of original and modified Q risk 2 risk score with Framingham risk score - an Indian perspective. Indian Heart J 73(3):353358. https://doi.org/10.1016/j.ihj.2021.01.016

40. Hippisley-Cox J, Coupland C, Brindle P (2017) Development and validation of QRISK3 risk prediction algorithms to estimate future risk of cardiovascular disease: prospective cohort study. BMJ 357:j2099. https:// doi.org/10.1136/bmj.j2099

41. Berry JD, Lloyd-Jones DM, Garside DB, Greenland P (2007) Framingham risk score and prediction of coronary heart disease death in young men. Am Heart J 154(1):80-86. https://doi.org/10.1016/j.ahj.2007.03.042

42. Andrus B, Lacaille D (2014) 2013 ACC/AHA guideline on the assessment of cardiovascular risk. J Am Coll Cardiol 63:2886

\section{Publisher's Note}

Springer Nature remains neutral with regard to jurisdictional claims in published maps and institutional affiliations. 